\title{
Scientific Literacy and Social Transformation
}

\section{Critical Perspectives About Science Participation and Emancipation}

\author{
Liliana Valladares ${ }^{1} \mathbb{D}$
}

Accepted: 16 February 2021/Published online: 10 April 2021

(c) The Author(s), under exclusive licence to Springer Nature B.V. 2021

\begin{abstract}
The paper provides a systematic theoretical analysis of the main visions of the concept of scientific literacy developed in the last 20 years. It is described as a transition from a transmissive educational vision of scientific literacy (Vision-I) to a transformative vision (Vision-III), with a stronger engagement with social participation and emancipation. Using conceptual tools from sociology and the philosophy of education, the notions of science participation and emancipation associated with transformative Vision-III are critically analyzed in order to draw attention to the growing need to define them with greater accuracy as key conceptual components of scientific literacy. Without such an approach, it will be difficult for science education to materialize and consolidate educational actions that are pedagogically sound, culturally and socially sensitive, and coherent with the social transformation of the diverse conditions of oppression. It is concluded that Vision-III should include both a broad conception of participation, which makes visible the invisible and informal acts performed by diverse groups to build society, and an alternative notion of emancipation committed to liberation.
\end{abstract}

\section{Introduction}

The recent crisis caused by the COVID-19 pandemic revealed numerous inequalities, gaps, and vulnerabilities in education. At the same time, it highlighted a range of possibilities and projections for shaping an improved education, one more suitable for global challenges. UNESCO (2020) presented nine big ideas to build the foundations of this post-pandemic education. One of these ideas raises the need to: “...Ensure scientific literacy within the curriculum. This is the right time for deep reflection on curriculum, particularly as we struggle against the denial of scientific knowledge and actively fight misinformation..." (UNESCO, 2020, p. 6).

The growing reaction of some citizens and political leaders, denying scientific knowledge about socio-scientific issues of planetary relevance, such as climate change or even the coronavirus pandemic, together with the diversity and multiplication of fake news

Liliana Valladares

lvalladares@comunidad.unam.mx

1 Facultad de Filosofía y Letras, Universidad Nacional Autónoma de México, Mexico City, México 
and unreliable sources of information regarding the techno-scientific risks to which we are exposed daily, has served as an alert to reactivate the global commitment to scientific literacy (Orozco, 2020; Nguyen and Catalan-Matamoros, 2020). This revival of science and technology in formal, informal, and non-formal educational settings makes it urgent to recover the question of why a scientific literacy is important and what is the meaning that this concept should have.

In general terms, the meaning of scientific literacy has changed throughout history and many definitions of this concept have been developed, which have basically migrated from a scientific teaching focused on the memorization of scientific concepts and laws, towards a scientific teaching focused on the study of its risks and impacts on society and, more recently, on the role of science as a tool for social change. Regarding the social function of scientific literacy, in sum, this has been located around three main orientations (Liu, 2009, 2013): as (1) the elimination of a cognitive deficit; (2) the acquisition of a personal commodity; and (3) a one-way transport towards a more valuable social end.

In the first case, when the term scientific literacy refers to a deficit elimination, it is assumed that students or the general public are illiterate in science and that this deficiency needs to be corrected, regardless the various types of knowledge and experiences people have regarding the natural world and without necessarily considering the context in which it is inserted. When scientific literacy is treated as the acquisition of a commodity, it is often assumed that once a student has achieved a certain result associated with science education and has crossed the threshold between what is considered literate and illiterate in science, this person has obtained an asset that will last forever, no matter what field of science he or she has managed to cross this threshold in, and ignoring both the dynamism of science and that learning is an endless and lifelong process. Finally, when scientific literacy is conceived as a one-way transport, it is understood as a carrier of different benefits, that is, the means that transport a society from a state of lesser to a state of greater knowledge and well-being, like, for example, when it is expected that scientific literacy is a tool for economic development and national security (Liu, 2009, 2013).

What kind of orientation should we aim for to guarantee a scientific literacy suitable for the challenges of the twenty-first century? Answering this question is neither simple nor trivial; all definitions have a scope and limitations and the picture becomes even more complex when we see the multiple typologies that have been generated in the specialized literature and that have sought to establish a clear definition of what scientific literacy actually is and what it should be.

This article is based on a documentary analysis that systematizes some of the main visions and meanings of scientific literacy. It describes how this concept has moved from a transmissive vision of the educational process, focused on the unilateral transmission of scientific knowledge and without a clear link to the social dimensions of science (VisionI), towards a socio-cultural and situated vision of the educational process (Vision-II), and, finally, to a transformative vision committed to participation and emancipation (VisionIII). This last one prevails in most of the recent studies on the research field in science education, in which it is emphasized that a scientific literacy for the twenty-first century should aim towards social activism.

Social activism in Vision-III is proposed as a response to the disturbing issues we-the whole of humanity-are facing. Undoubtedly, we are experiencing a strong security crisis and we are dealing with different forms of violence and systematic violations of human rights that are intertwined in a global context characterized by a political and environmental crisis that could be synthesized in challenges such as climate change, increasing mass migrations, the excessive circulation of misinformation-fake 
news - and the massification of digital technologies. Moreover, one could add a global context full of catastrophic global risks, among which we should mention the recent pandemic produced by the SARS-CoV-2 virus. The COVID-19 pandemic has evidenced how all human relationships are burdened with injustice, economic and cultural fragility, and social inequality. In the same way, the pandemic has made visible how day by day these gaps widen and the conflicts between countries are escalating and how, paradoxically, all these divides advance along with an unprecedented techno-scientific development, which raise doubts about their own ethical limits, given the possibility of creating new transhuman and post-human species; this scientific progress is capable of profoundly redefining the relationships between nature, culture, and human beings, but has shown to be unable to include all people equally in the benefits of science and technology.

This set of social problems is configured by, at the same time it configures, chaotic, turbulent, and changing environments that are accelerated by globalization, leading us towards to what is known as the VUCA world. VUCA is an acronym that refers to the volatility, uncertainty, complexity, and ambiguity (Bennett \& Lemoine, 2014) that characterize current social, ecological, political, and economic systems that make the twenty-first century increasingly more and more difficult to precede and manage. Coping with these challenges requires a flexible scientific literacy, committed to social transformation. In the context of this article, social transformation refers to social change and rupture of the distinct oppression structures (based on racism, sexism, classism); it means the transformation of the historical, ideological, institutional set of policies, practices, traditions, norms, and discourses which, based on prejudice, discrimination, and differential power, work to systematically exploit and exclude different social groups (minoritized, dominated) for the benefit of other social groups (dominant) (Sensoy \& DiAngelo, 2017).

In order to change the systemic injustice that keeps certain groups excluded from the benefits of scientific-technological development, requires a trans- and interdisciplinary approach. On the one hand, an interdisciplinary approach enables two or more disciplines to interact in order to allow for an object of study to be described, analyzed, and understood in all its complexity through collaboration, synergy, and disciplinary integration, which may consist of the transfer or appropriation of concepts, values, and methods from one discipline to another. On the other hand, a transdisciplinary approach contributes to shaping much more systemic, global, and multidimensional visions of an object through a complex knowledge process that exceeds disciplinary limits.

A comprehensive understanding of scientific literacy, which encompasses all its complexity and dimensions, requires at least the interdisciplinary interrelation of various fields of study. Otherwise, bringing ideas from a single discipline to conceptualize scientific literacy could result in a fragmented and limited vision of the concept, without attaining a unified vision that integrates and facilitates moving towards new epistemologies, ontologies, and methodologies in the field of science education.

Hence, reviewing some categories developed by the philosophy of education, for example, would allow us to clarify and justify the why of the different educational practices of science, as well as to solve fundamental questions about the ultimate ends of human being, society, culture and science, their relationship with the aims of education, and the principles on which certain pedagogical practices are designed and constructed. Similarly, through a sociological view, interdisciplinarily articulated with the philosophy of education, we would be able to analyze the structural logics that condition the social and educational practices, understanding the different ways in which society is conceptualized, 
historizing the inequalities and diversities that most of the times are assumed as natural; with the sociological approach, we would be also able to de-essentialize and de-substantialize the social problems that are manifested and reflected in the science classroom, and which often determine the students' educational success.

To change society by means of science education, it is important first to understand what features of society we want to modify and why. This necessarily implies knowing how society is structured, how it works, and what place education, culture, and science education occupy in said social structure. The same can be done by interrelating the contributions of other disciplines - such as history, economics, or the politics of education-to highlight some of the disciplines whose participation is necessary to configure a broad and critical concept of scientific literacy.

In this article, I expect to encourage this interdisciplinary conformation of a broad notion of scientific literacy, taking some contributions from sociology and philosophy of education as analytical tools, which allow to analyze the notions of "participation" and "emancipation," which are strongly associated with the transformative vision of scientific literacy (Vision-III). I explore only these two notions from the point of view of two disciplines, because I consider these sufficient to exemplify the potential that an interdisciplinary reflection would have in the critical reconceptualization of the different components that make up scientific literacy. Although this analysis does not delve exhaustively into the interdisciplinary construction of the concept of scientific literacy, it does illustrate how the analytical tools taken from different disciplines can contribute to refine this concept. I have chosen to work with these two notions because of the strategic role they have in the transformative vision of scientific literacy, so the title has been referred to as critical notes on participation and emancipation. Their key role becomes evident when the main trajectories and conceptual changes on science education over time are described in the first sections of this paper, showing the urgency of a critical approach to the meanings of scientific literacy's components.

The critical character of the notes that are developed in this text refers to the relevance for the science education field of paying attention to the need to pause for a moment and to elaborate a conceptual analysis of the notions of science participation and emancipation implied in the literacy process, and to underscore that these notions have multiple interpretations (sociological, political, philosophical, historical, etc.) that are not visible to the naked eye. As it is referred by Collins and Bilge (2016), the term "critical" is a qualifier that means "... criticizing, rejecting and/or trying to fix the social problems that emerge in situations of social injustice..." (p. 39), because it is only through the task of uncovering the injustices behind social inequalities that it becomes possible to "... imagine alternatives, and/or propose viable action strategies for change..." (Collins \& Bilge, 2016, p. 40). So, given the exclusions and oppressions that take place in diverse educational contexts, there is an urgent need for a commitment to those definitions about participation and emancipation that have an engagement with either unmasking hierarchical and asymmetrical relations of power and with the transformative character produced by participation and emancipation in science education for reordering and fixing social relations in science school and society. In other words, the brief conceptual review that is presented in this paper maintains a critical stance in the sense that it defends the need to expose how the concepts of science participation and emancipation are intersected by the axis of power, by relationships of inequality (social, cultural, economic), domination, and social exploitation, which are manifested in diverse forms, combinations, and complexities, across different processes and practices of scientific literacy. These are critical notes as they explore, conceptually, the historical and practical possibilities of a transformation of educational 
realities in the context of science education, letting the reader figure out alternatives for educational research and change in this field.

Specifically, what makes these notes "critical" is, therefore, their affiliation to the main two principles through which Gottesman (2016) characterizes all critical thinking in education: (i) the principle of relationality, that is, to assume that educational practices and institutions along with social and cultural relations need to be seen as intimately connected to the inequalities that structure modern societies, seeking all the time to transform them, and (ii) the principle of repositioning, which refers to the commitment and interest of those educational investigations that look for an understanding of educational actions developed from the point of view of the connections among the many dimensions of society as a whole, as well as from the point of view of the dispossessed and disadvantaged ones, for transforming and acting against the ideological and institutional processes that reproduce and perpetuate the conditions of oppression. In this sense, these notes share the aspiration of the critical thinking in education to broaden the conceptual scope to which Vision-III of scientific literacy invites us, offering a couple of theoretical-methodological elements, such as intersectionality in participation and emancipation as disidentification, which both underpin and demand a transformation of social structures, institutions, and relationships towards societies in which major conditions of plurality, symmetry, equity and equality, and mainly social and educational justice prevail.

This paper is organized as follows: Section 2 reviews the fundamental and derived meanings of the concept of scientific literacy in order to show one of the first changes that this concept underwent and that describes how this literacy overcame to be limited to reading and writing scientific texts, spreading its scope towards the social field, adding a derived sense that included the development of multiple skills associated with the role of science in society. Simultaneously to the change in the fundamental sense of scientific literacy, the notions of participation and emancipation will later emerge as key components of the derived sense of the concept.

Given the myriad of conceptions that derived sense brought with it, in Section 3 Visions-I and -II are described as conceptual strategies that help to map, organize, and synthesize the explosion of multiple conceptions about scientific literacy. Later, in Section 4 , the transformative view of scientific literacy is presented as a broader and more critical elaboration than those offered by Vision-I and -II. In this section, emancipation and participation are explicitly introduced as core components of a scientific literacy oriented towards social transformation. Although incorporating these two components in the field of science teaching has been a very important step in the historical development of the concept, because it shows a close co-constitutive relationship between science, society, and science education, Section 5 discusses how both notions, participation and emancipation, require conceptual precisions, since they are lived and experienced differently and unequally according to variables like class, ethnicity, and gender of those who enroll in a science education process, so it is necessary to explore the deeper meanings of these two conceptual components. In this way, in Section 5.1, a brief analysis of the meaning of science participation from an intersectional perspective is carried out, and in Section 5.2, an analysis of emancipation from a philosophical perspective is developed.

By deepening into the meanings of both terms, the intention is to account for the urgency and richness of taking categories discussed in the philosophy and sociology of education to define a scientific literacy in a way that is more compatible with the diversity of conflicted, cultural, and social experiences in which students and teachers are inserted; thus, the intent is to be more in line with the volatility, uncertainty, complexity, and ambiguity associated with the challenges of the twenty-first century. This critical contribution 
has the ultimate purpose of claiming that the pretensions to universalize and simplify the character of scientific literacy entail the risks of, on the one hand, underestimating some conceptual precisions that are necessary to design and materialize educational actions which are pedagogically sound, and directed towards the social transformation proposed in Vision-III, and, on the other hand, of turning this concept into the opposite of its transformative purpose, that is, into a concept that, instead of strengthening students' participation and emancipation, contributes to the reproduction of socioeducational dependencies and cultural exclusions in the field of science.

\section{The Fundamental and the Derived Sense of Scientific Literacy}

The term "scientific literacy" originated in the 1950s to express a set of goals for science education (Bybee, 2016; Choi et al. 2011). During the 1990s, with the circulation of educational reform documents in the USA and other countries, scientific literacy became the most important goal of science education. Although many efforts were made to define it, today there is no universally accepted definition of this concept (Liu, 2013).

Roughly, this literacy could be defined as "being educated and possessing knowledge in and about science" (Norris \& Phillips, 2016, p. 947). However, this definition could become more complex and give rise to large and specific categories that show the multivariate nature of elements contained in scientific literacy. That is the case of the contributions of Norris and Phillips (2003), who organized the multiple definitions of this concept in two senses: the fundamental and the derived sense.

Norris and Phillips (2003) identified that scientific literacy is most often used to refer to one of the following aspects: knowledge of the substantive content of science and the ability to distinguish what is and what is not science; understanding of science and its applications; ability to think scientifically; ability to use scientific knowledge in problem solving; knowledge needed to participate in socio-scientific issues; understanding of the nature of science and its relationships with culture; assessment of the benefits and risks of science; ability to think critically about science and deal with scientific expertise.

Given this multiplicity of conceptions, and since they frequently comprise a multidimensional set of diverse elements to assess what it means to be scientifically literate, Norris and Phillips (2003) underscore the importance of distinguishing between a fundamental sense and a derived sense of this term. According to them, most of the conceptions found in literature appeal to the derived sense, forgetting its fundamental sense.

In their approach, Norris and Phillips (2003) refer to the most basic meaning of "literacy" as the ability to read and write, and they differentiate it from a derived sense that understands this term as knowledge, learning and education. A person can have knowledge about something, as Norris and Phillips (2003) point out, “...without being able to read and write..." (p. 224), but when it refers to a disciplinary body of knowledge, such as science, the connection between specialized knowledge and the ability to read and write is closer, even more when it is acknowledged that scientific practices are predominantly textual, to such an extent that it is impossible to know science without reading, writing, and exchanging scientific texts. It implies that the fundamental sense of literacy should also be the fundamental meaning of scientific literacy, and yet it is precisely the most absent sense in the literature (Norris \& Phillips, 2003).

Certainly, it is not easy to find a definition of scientific literacy that recovers this fundamental sense. This neglect of including the reading and writing of scientific texts as a basic 
definition of scientific literacy is also reflected in the educational practice of school science that usually underestimates the importance of the fact that "...scientists create, share and negotiate the meanings of inscriptions: notes, reports, tables, graphs, drawings, diagrams..." (Norris \& Phillips, 2003, p. 225). Through texts, scientists present and represent data; elaborate and communicate hypotheses, models, theories, arguments; codify and systematize the productions of other scientists; re-examine ideas published within and outside their field, among others.

According to Norris and Phillips (2003), reading and writing are not only communicative or storage tools of science, which implies science could therefore be extracted from them; these activities are also constitutive of science practices, and without them there is no science as such, neither inside nor outside the school. Following these authors, we should overcome the traditional belief that reading and writing are passive activities and not very significant for the learning of science, and give rise to proposals of academic literacies that reclaim the relevance of scientific texts as science's fundamental pieces. As Norris and Phillips (2003 p. 236) argue: “...Nobody can acquire a sophisticated level of scientific knowledge without being literate in the fundamental sense, and science itself could never exist without individuals literate in this way...".

However, this fundamental sense has been blurred and scientific literacy is usually defined only by its derived sense. According to Bybee (2016), outside of the boundaries of learning to read and write, scientific literacy is referred to as the understanding of science and its applications in the individual and citizen experiences, and it goes back to 1958, with P.D. Hurd's contributions, who figured out what is perhaps one of the first definitions that link science curricula and educational resources to provide students with opportunities to appreciate science as a human and intellectual achievement; to use scientific methods and to apply science to the social, economic, political, and personal domains (Bybee, 2016).

Among the many attempts to describe the derived sense of scientific literacy and to systematize its elements (DeBoer, 2000), the effort by Choi et al. (2011) is relevant. Based on a deep documentary review and a wide set of opinions from science teachers form different levels, Choi et al. (2011) outlined a scientific literacy definition for the twenty-first century, made up of five dimensions: (i) Scientific contents; (ii) mental habits (communication and collaboration, systematic thinking, information management, use of evidence and argumentation); (iii) character and values to act responsibly; (iv) science as an activity (its epistemology and its relations with society); (v) metacognition and self-direction (selfmanagement and self-evaluation).

This is perhaps the most exhaustive definition to date of the derived sense from the concept, both because of the diversity of elements it contains, and because of the participatory methodology with which it was constructed, reminding us that the concept should also be meaningful to all those agents who participate in the literacy process (teachers, but also students, science education researchers, decision makers on educational and scientific policy, and the general public).

Another remarkable effort to understand the derived sense is Roberts (2007), who not only achieved to place scientific literacy on the international agenda of educational policies, but also organized the multiple conceptions into two main visions. More recently and based on Robert's contribution, a third vision of scientific literacy has been developed to summarize the current understanding of the concept.

The distinction between the fundamental and derived senses of scientific literacy represent one of the first steps that enabled overcoming a narrow vision of science in the school context, based on the idea that learning science is only acquiring skills to read, write, and handle scientific information. The result was an explosion of multiple definitions, many of 
them listings of competences that tried to condense the derived sense of scientific literacy; this derived sense allowed to relate science learning with the gradual development of a set of different skills associated with the scientific activities and their historical, social, cultural, political, and environmental implications.

\section{Vision-I and Vision-II of Scientific Literacy}

According to Roberts (2007), and in parallel with the two modes of scientific knowledge production developed by Gibbons et al. (1997), there are two main views of scientific literacy that can be distinguished, and which encompass almost all definitions of this term (Bybee, 2016; Sjöström \& Eilks, 2018). These visions make up a continuum and are recurrently cited because they help to map, organize, and conceptualize the diversity of conceptions about this term (Liu, 2013). Following Roberts (2007), while the so-called Vision-I is rooted in the products and processes of science, Vision-II is anchored in social situations with a scientific component, which students will face as citizens.

Vision-I focuses on the learning of scientific contents and processes for their subsequent application (Bybee, 2016); it emphasizes science as a discipline that demands propositional and procedural knowledge, metacognition, and disposition (Liu, 2013). This orientation is linked to what Aikenhead (2006) called "science to prepare future scientists." Vision-II includes the scientific literacy definitions focused on understanding the usefulness of scientific knowledge in life and society, and on fostering its learning from meaningful contexts (Bybee, 2016), contextualizing it and relating it to technology, environment, and society (Liu, 2013). This orientation is identified with the Aikenhead (2006) orientation of "science for all." This second vision adopts a socio-cultural perspective of teaching and learning and recognizes that science is not only an isolated content, but also involves a context of cultural connotations (values, beliefs, emotions) related both to the social and individual life of students, and to the historical, philosophical, and socio-cultural dimensions of science. Vision-II is developed as a product of what Mansour and Wegerif (2013) called the "socio-cultural turn in science education," in which the decontextualization of knowledge that characterizes Vision-I is questioned. This socio-cultural turn incorporates science into a context of cultural practices and interests that demand attention from the school; schools could no longer remain blind to the students' culture and were now required to understand personal/collective students' ideas about science.

Each vision gives rise to very different curricular proposals, strategies, and instructional resources, as well as different evaluative designs, roles, and strategies for teacher training (Bybee, 2016). For example, while Vision-I is present in the TIMSS-OECD assessments, with textbook questions without context, Vision-II is present in type PISA evaluations designs, characterized by contextualizing their items (Bybee, 2016; Liu, 2013).

Roberts' two visions represent an effort to synthesize the multivocity of scientific literacy that was the result, to a large extent, of the theoretical development of Science, Technology, and Society (STS) studies and social theory, which enriched the reflection on the effects of scientific and technological activities on societies, showing the need to contextualize scientific practices. As STS studies and social theories about science in general became more complex, so did the visions of scientific literacy. These two visions are a mirror reflection of the contrast between a positivist image of science isolated from the society, whose teaching practices were focused on achieving the canonical concepts of science 
(Vision-I), and a postpositivist science, linked to society, whose teaching practices changed focuses on the technological and social context in which science is developed (Vision-II).

However, as STS studies gradually advanced, they started to explore the ways in which science and technology co-constitute the world, the objects, the values, the institutions, and in short, all society and culture-and vice versa-so it became evident that in the science education field, it was necessary to take another step in the relationship between science and society. When STS studies explained how society and culture are co-constructed by science, this co-construction of science and society demanded a new vision of scientific literacy. As a response, since the last decade, a third orientation has been added to these two visions-Vision-III-which is the result of the contributions and reflections of Santos (2009), Yore (2012), and Liu (2013).

\section{A Transformative Vision of Scientific Literacy}

Vision-III expands the conceptual scope of scientific literacy developed in Vision-II, and assumes school science beyond its social contextualization, as involving a greater social engagement and citizen impact (Sjöström \& Eilks, 2018).

This new vision integrates three innovative aspects: 4.1: a fusion of the fundamental and derived senses of scientific literacy (Yore, 2012); 4.2: an introduction of the notions of science engagement and participation (Liu, 2013); and 4.3: the inclusion of a political and emancipatory agenda aligned with values such as equity and social justice (Santos, 2009).

Together, these three aspects make Vision-III more in line with the challenges of the twenty-first century, because in order to transform human relationships and consequently the different systems of injustice, economic, cultural, and social gaps, and to change the growing expressions of hate and violence towards certain social groups as well as to stop the exacerbation of environmental crisis, it is not enough to contextualize science and reflect on its multiple risks and impacts, but rather a different orientation of science education and a set of skills that promote greater social activism and individual and collective agency are required. That is, science education should not settle for teaching practices focused on reading and writing scientific texts but should promote a more disruptive literacy based on the use of scientific content and the critical thinking characteristics of science. This new vision should permit a better search for the comprehensive understanding of complex and long-term processes we are facing in the VUCA world, so in this way, science education could foster a more equitable distribution of the benefits of science to build more global resilience, projecting new anti-oppressive and more supportive and sustainable social relationships, not only among human beings, but also between them and the environment.

\subsection{Fusion of the Fundamental and Derived Senses}

Yore (2012) considers that the two senses initially differentiated by Norris and Phillips (2003) are separated in Visions-I and -II of scientific literacy and proposes to merge them to constitute a Vision-III.

Vision-III is an additive socio-cognitive scheme composed of two sets of knowledge and skills about science: on the one hand, those related to the fundamental sense of being a science-literate person, which includes cognitive skills - such as critical thinking - and metacognitive, affective, communicative, and technological capacities; on the other hand, 
those related to the derived sense of scientific literacy, that is, knowledge about science and scientific practices, its relations with society, technology and environment, an understanding of natural events, and the big ideas and unifying concepts of science, which allow for a greater participation and science engagement in a social context.

\subsection{Science Engagement and Participation}

According to Liu (2013), a significant change in the orientation of scientific literacy and its humanization requires a new vision that goes beyond Visions-I and -II, and it should be characterized by what is called a "science engagement" since: " ... the understanding of science as well as its relations with technology and society by individuals is not enough; active participation and dialogue among all citizens on complex issues are needed..." (Liu, 2013 p. 27).

Science engagement, in Liu's perspective, refers to promoting active participation in the public debate around science and the search for solutions to relevant socio-scientific issues that the world is facing today, emphasizing the multidimensionality of science. Liu (2013) assumes that, with the idea of science engagement, Vision-III preserves all the conceptual benefits gained by Vision-II (i.e., contextualizing science), but also are summed up by another conceptual advantages as the closing of the gap between the two cultures (the scientific and the humanistic, in the first place, but also between rich and poor, East-West, science-technology, among others).

Science engagement is both "...a state and a lifelong process..." (Liu, 2013, p. 36) that develops throughout life, and that can be expressed and measured gradually at levels or domains which are defined differently according to diverse typologies that conceive scientific literacy as a gradual, measurable, and discretionary concept.

Hodson's typology (1999; 2003), for example, identifies four levels of mastery in scientific literacy: level 1, in which it is possible to understand and learn science and technology conceptually; level 2, in which it is possible to learn about science and technology, its nature and relations with particular interests along with the different forms of distribution of wealth and power; level 3, in which it is possible to do and practice science and technology; level 4, in which a science engagement is consolidated and expressed in sociopolitical actions. Vision-III aims to reach level 4, that of greater science engagement, manifested as an activist and transformative education (Bencze, 2017; Sjöström \& Eilks, 2018). Other typologies that classify the science literacy process according to the level of science engagement are those of Shen (1975) and Shamos (1995).

The different degrees of science engagement among the three visions also reconfigures the role of students in scientific literacy. While in Vision-I students engage in science for developing their intellectual capacity and for preparation of a science career, that is, they are "pure science learners" (Liu, 2013, p. 29), in Vision-II, they engage in science for solving technological and societal problems, as "science advocates" (Liu, 2013, p. 29). In contrast, in Vision-III, students seek the best-informed solutions to complex social, cultural, political, and environmental issues as "honest brokers" (Liu, 2013, p. 29), expanding the range of options for decision makers.

Science engagement also means addressing science ethically. Vision-III encourages the debates about science benefits and risks and analyzes the possibilities of its fair distribution and sustainable use (Santos, 2009). This feature makes Vision-III correspond greatly with the SSI (socio-scientific issues) approach (Sadler \& Dawson, 2012; Zeidler \& Nichols, 2009), perhaps the most popular proposal in STS education (Pedretti \& Nazir, 2011), 
oriented to cultivating the humanistic aspects of science and students' character formation as future global citizens (Lee et al. 2013; Zeidler et al. 2019).

Regarding the relationship between the notions of participation and emancipation, it could be stated that, although they are both diffuse and buzzwords, participation is, generally, one of the key indicators of the level of science engagement (DeWitt \& Archer, 2017). A higher participation in some social, educational, or cultural process will almost always correspond to a maximum level of engagement (Montero, 2004), while a marginal participation will correspond to a lower or no engagement. As Fredricks et al. (2004) argue: “... participation at the upper levels indicates a qualitative difference in engagement in terms of greater commitment..." (p. 62). This means that both terms can be treated as interchangeable concepts; however, they are not the same: engagement is a more comprehensive concept than participation, and its conceptual treatment requires greater complexity, which for the purposes of this article is unnecessary, since working with the notion of participation is sufficient as a reflection or indicator of a greater or lesser science engagement (DeWitt $\&$ Archer, 2017). Based on the contribution on school engagement elaborated by Fredricks et al. (2004), authors such as Woods-McConney et al. (2014) and Grabau and Ma (2017) suggested that science engagement is a multidimensional concept that comprises, at least, three components: (a) the behavioral, which refers to participation in science or science-related activities, both formally and informally; (b) the emotional, which embraces (positive or negative) affective responses to science, but also attitudes in science, including interest, boredom, happiness, sadness, and anxiety; (c) the cognitive, related to the extent to which students are willing to develop science concepts and skills, their motivation, selfregulation, and their interest and investment in learning and schooling. Science participation is therefore only one of the science engagement components (Woods-McConney et al., 2014), related to "...how individuals become involved in something or with someone, such as science/scientist..." (Wong, 2016, p. 117); this notion has a behavioral nature, implying the activation of particular actions, mainly the action of taking part in science, either as an individual or as a part of a community (Bee \& Kaya, 2017), within and beyond the context of the school (DeWitt \& Archer, 2017).

Science engagement involves taking more risks, greater spontaneity, motivation, and creative action (Hoffman et al., 2005) with the processes of generation, distribution, and use of scientific knowledge for individual and collective life. People engaged with science seem most likely to get involved in a scientific enterprise with an uncertain outcome and in which they have much at stake; seem to feel greater spontaneity and freedom to discover, change, believe, and participate in processes of science; seem to experience an increased motivation to take action and creative agency (Chang et al., 2007; Fredricks et al., 2004; Johnston et al., 2015; Wong, 2016). Science engagement translates into greater opportunities to experience a more intense relationship with science in everyday life and this is, in turn, results in a deeper participation in which personal and collective agency indicates a greater conviction and deeper understanding of the relevance of science as a process of generation, distribution, and use of scientific knowledge necessary, valuable and useful for everyday life, and in particular, to cope with the challenges of the twenty-first century (DeWitt \& Archer, 2017; Grabau \& Ma, 2017; Levinson, 2010).

\subsection{Critical and Emancipatory Approach}

Vision-III is also characterized by its rooting in critical theories of education, which emphasize empowerment and the transformation of social power structures. This feature 
contrasts with Vision-I, in which the conceptual change approaches are predominant and focused on the dynamics of students' scientific ideas and their approach to formal scientific understandings, and with Vision-II, anchored in the socio-cultural theories of students' activity (Liu, 2013).

In this way, Vision-III could be identified with Hodson's so-called critical scientific literacy (2009), where the students' engagement is geared towards socio-political action to face global concerns and relevant societal problems (Sjöström \& Eilks, 2018). The humanization of science is also reflected in the interest in developing the students' capacity to think critically about science and deal with scientific experience in a complex society (Ravetz 1997; Norris \& Phillips, 2016).

The incorporation of a critical position about science in Vision-III goes back to the contributions made by Santos (2009). Inspired by Paulo Freire's texts, Santos draws attention to how scientific literacy, in the same way as all types of education, is not neutral and should have a political agenda that includes the social contradiction and conflict present in all societies and displayed in diverse issues such as unequal access to technology, its power of domination, the oppressive context of technological markets, and almost in every single aspect of modern societies in general. Santos takes from Freire the fact that human beings are inserted within contexts of oppression and alienation and that literacy, in addition to teaching reading and writing, should represent a possibility for transforming these conditions of exploitation.

According to Santos, "a radical vision of scientific literacy" should contain "... a political agenda to science education that would include issues such as unequal access to technology around the world, the domination power of technology, and the oppressive context of scientific and modern technological society..." (Santos, 2009, p. 362). Thus, the development of Vision-III recovers Freirean approaches, and deepens the educational engagement to change oppression and alienation, humanizing school science and transforming the inequitable social reality of the globalized world.

Fundamental to Vision-III, therefore, is the notion of emancipation, understood as "eliminating oppression and creating conditions for effective agency" (Sjöström \& Eilks, 2018, p. 71); by becoming emancipated, students can become moral agents, responsible and proactive citizens able to collaborate and communicate in order to participate in public discourses and actions to resolve SSI in a manner that is fair, equitable, and committed to the local and global common good (Lee et al., 2013).

Vision-III's critical and emancipatory character is also present in its active, interdisciplinary teaching strategies, situated in the uncertain and complex contexts of real life, and oriented towards decision-making, ethical reflection, social action, transformation, and empowerment. These strategies, as highlighted by Pedretti and Nazir (2011), are traditionally outside the repertoires of science teachers aligned with Vision-I.

Vision-I strategies are transmissive, content-centered, and regard values and interests as obstacles to science, relegating and avoiding controversial issues such as risk, uncertainty, ignorance, and resilience, all characteristics of the VUCA world (Ravetz 1997; Bybee, 2016; Sjöström \& Eilks, 2018; Bennett \& Lemoine, 2014).

Table 1 synthesizes the contrast among Visions-I, -II, and -III of scientific literacy and depicts Vision-III as the fertile space for developing a transformative scientific literacy and for breaking with the reproductive and transmissive character present in the first two visions.

Table 1 is the result of merging the contributions made by Liu (2013) and Sjöström and Eilks (2018) and of problematizing the axis of the relationship between science and society. Each vision proposes particular aims for scientific literacy, and based on them, the ideals 


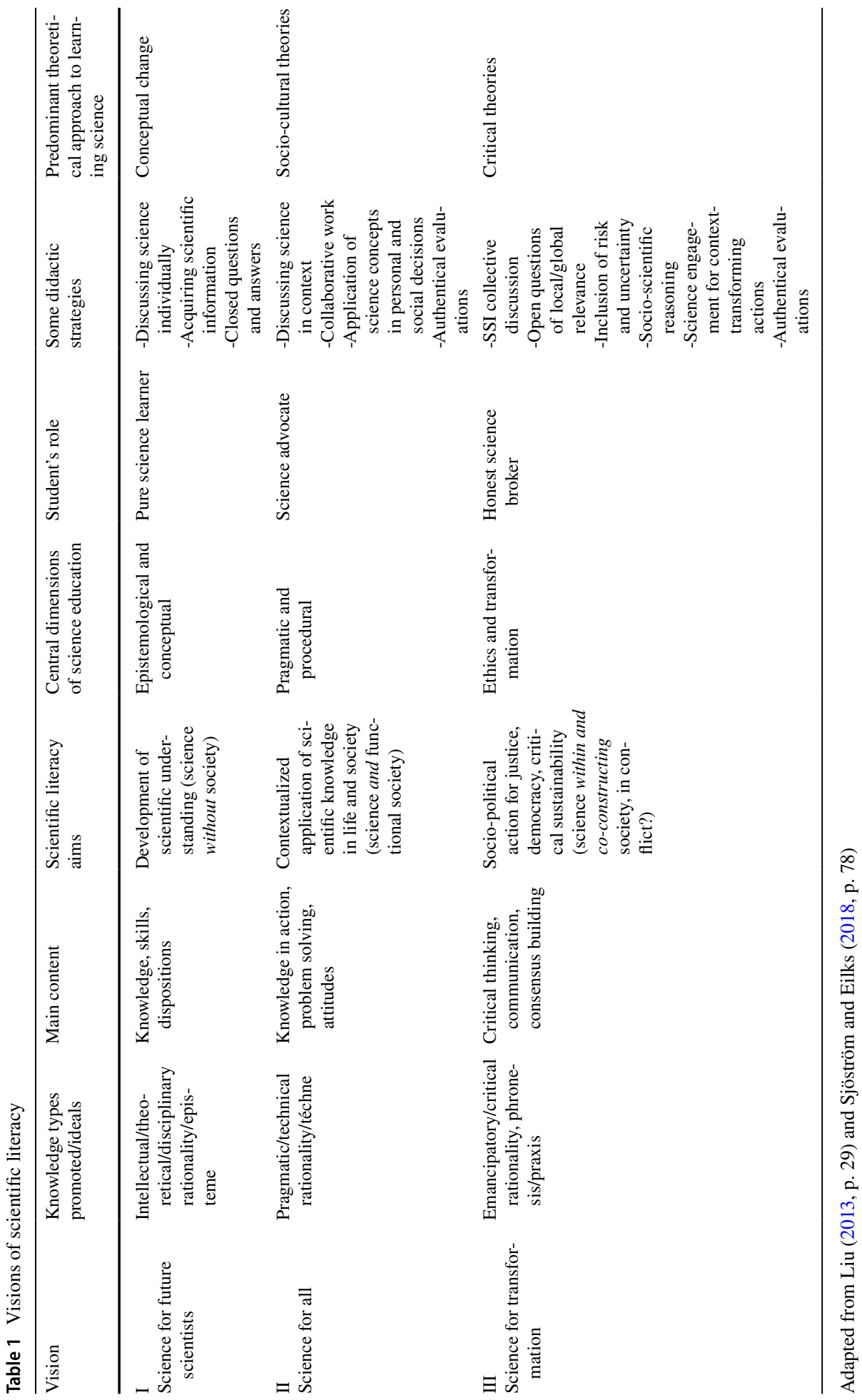


and central dimensions for the process of science education are defined. Likewise, each vision assumes a role for the student and gives preference to certain didactic strategies. Thus, for example, as illustrated in Table 1, Vision-I is configured around a science thought without society, isolated and focused on the conceptual and epistemological dimensions of scientific enterprise. The theoretical approach of conceptual change is predominant in Vision-I, and therefore, the main content in science school is scientific knowledge as the main product of science, which must be taught mainly through transmissive strategies aimed at information acquisition. Vision-II, on the other hand, as it integrates sociocultural theories, considers science in its relationship with society, but this relation is limited as much as society is only the context in which science happens. Didactic strategies in VisionII emphasize the discussion and application of science in context, problem solving, and, with this, the pragmatic dimension of science is promoted. It is important to say that in both visions, I and II, the relationship between science and society remains distant. In contrast, Vision-III delves deeper into the ethical, social, and transformative aspect of science, since it is thought of as constituting and being constituted by the society. While in VisionII society is conceived in a functionalist sense, in Vision-III, it is not yet clear if society is conceptualized in a post-Marxist sense, namely, in conflict and contradiction beyond social class. Rooted in critical theories, Vision-III is driven by the emancipatory ideal and, rather than concentrating on the teaching of scientific knowledge and its application, the formative process encourages critical thinking and socio-scientific reasoning through SSI-type didactic strategies, in which the notion of praxis is key as a measure of the materialization of human agency, and as an action that constructs reality, thereby transforming the world.

From Liu's (2013) perspective, these three visions depend on each other and should mutually enhance each other; educational efforts should not focus on just one of them and ignore the other two, as all three form a continuum. Vision-III's core goal, Liu (2013) argues, is to promote a more democratic and harmonious society through a stronger engagement between science and society. Likewise, Yore (2012) maintains that Vision-III has implications for general literacy for citizenship and daily life, since it demands engaging in and with science participation (through confrontation and/or dialogue), without excluding the implications of Vision-I, oriented to the academic preparation to pursue science careers.

One of the main challenges for consolidating Vision-III is to convince responsible politicians, administrators, and teachers that scientific discourse and the learning of science have a functional role in the public debate about issues related with science, technology, society, and environment (Bencze, 2017); it is also relevant to show the unavoidable cognitive symbiosis between the fundamental and derived senses of scientific literacy to achieve the society we want, in which science is appreciated as one of the best ways to generate reliable and robust knowledge (Yore, 2012).

Despite Vision-III's conceptual advantages, it does not address the possibility conditions required to materialize a scientific literacy sensitive to the diverse contexts of social and cultural positions from which science students start an educational process and where they live and give sense to science. An indigenous, female, lesbian, Latina student will not have the same opportunities to deploy and realize a science engagement as a male, white, heterosexual, European student. Consequently, it becomes urgent to scrutinize the differential meaning of some conceptual components associated with Vision-III, such as science participation and emancipation and, of course, its pedagogical implications in the roles acquired by teachers and students in a science classroom.

This paper argues that if we want to ensure the continuity of science education and promote its public value, it is not enough to convince society of the functional and critical 
role of scientific literacy as proposed in Vision-III if this conviction does not go hand in hand with a sound foundation of what scientific literacy means in the plural, diverse, and conflicted contexts in which students live. With students living in unequal conditions of oppression, science education demands a real belief in the relevance of creating new and differentiated scientific literacy opportunities that truly guarantee that science participation and emancipation derived from school science effectively takes place for all students, whose relations with science will be always situated at some point within this diverse and conflicted society.

The present text advocates the theoretical need to critically analyze the notions of "science participation" and "emancipation" contained in Vision-III, making use of tools from the philosophy and sociology of education. These analytical tools allow us to emphasize the conceptual biases and inaccuracies that are present when defining scientific literacy, and that should be addressed in order to configure a set of future educational practices that are more sensitive to the diversity of meanings of scientific literacy, and that consider the structures of oppression that go through all socio-educational processes.

Given that not all students have the same conditions and opportunities for science participation and emancipation, nor do they have all conceptions of scientific literacy or have stopped to think and reflect on this point and its implications in educational practice, the next section argues that having more precise and extended definitions of participation and emancipation in the field of science education could be useful both to broaden our analytical frameworks, which allow us to make visible the different subaltern ways in which members of diverse cultural communities and social groups establish relationships with science, and also to design science teaching and learning experiences that are more plural, inclusive, and sensitive to the different positionalities that science students occupy in the social structure.

\section{Is Scientific Literacy Really Equal for All?}

In the previous section, the analysis of Vision-III shows that there has been an important shift from a transmissive vision of scientific literacy to a transformative one, bringing the aims of science education closer to those of citizen education (Bybee, 2016; Yore, 2012). With this change, notions such as participation, emancipation, and social transformation have been strongly included. Nevertheless, these notions have received a superficial treatment and, consequently, some of their sociological, philosophical, and pedagogical implications have not been correctly addressed. This section argues that Vision-III does not deal with the fact that the experience of science participation, emancipation, and social transformation is lived differently and unequally according to variables like class, ethnicity, and gender. There is no doubt that students have an unequal access to science education based on gender, cultural background, and social identity (Mansour \& Wegerif, 2013). It also reveals that, depending on how emancipation is understood, there is a risk of reproducing relationships of dependency between the emancipated and the emancipators.

A more critical and deeper approach to Vision-III could be enriched by considering the analytical contributions of theoretical tools derived from sociology and philosophy of education, among them: (1) the intersectional analysis of the notion of science participation, which allows to account for how the structures of inequality and oppression that permeate every educational process also condition and determine the meaning of participation, and 
(2) the philosophical analysis of the notion of emancipation, which needs to be defined more precisely, since in the light of pedagogical reflection, it appears as a contradictory and complex notion which conditions and determines teacher-student relations.

\subsection{Science Participation: Brief Analysis from Intersectionality}

Intersectionality cannot be understood if we do not first assume the existence of a systematic exclusion and oppression of individuals and groups that has become normal in society, and therefore, an invisible practice (Sánchez \& Gil, 2015). The homogenization of diversity, on the one hand, and social categorization, on the other, result in social and educational inequalities sustained by arbitrary hierarchies that legitimize the exclusion of some groups and individuals who are simply considered sub-citizens, restricting their access to the same educational, economic, social, political, and cultural opportunities and rights.

In the case of education, exclusion and oppression are historical, ideological, institutional, and embedded in culture in at least the following systems of power (Sensoy \& DiAngelo, 2017): (1) Racism: form of oppression associated with colonialism; (2) classism: associated with the capitalist economic model; (3) sexism: rooted in patriarchy.

Collins (2015) states that intersectionality is “...the critical insight that race, class, gender, sexuality, ethnicity, nation, ability, and age operate not as unitary, mutually exclusive entities, but as reciprocally constructing phenomena that in turn shape complex social inequalities" (p. 2). Intersectionality represents a:

...new way of looking at social inequalities and possibilities for social change. Seeing the social problems caused by colonialism, racism, sexism, and nationalism as interconnected provided a new vantage on the possibilities for social change. Many people came to hope for something better, imagining new possibilities for their own

lives and those of others... (Collins, 2019, p. 1).

Harris and Patton (2019) consider intersectionality as a critical analytic lens to interrogate disparities in structures of inequality. Collins and Bilge (2016) propose intersectionality is "...a way of understanding and analyzing the complexity in the world, in people, and in human experiences..." (p. 2) and “...a more sophisticated map of social inequality that goes beyond class-only accounts..." (p. 16). Cho et al. (2013) complement this definition by asserting that intersectionality is "... an analytic sensibility [...] to explore the problem of sameness and difference and its relation to power..." (p. 795). According to Maina-Okori et al. (2018), intersectionality is a framework to deconstruct and disrupt oppression, challenging hegemonic structures such as patriarchy, colonialism, capitalism, and anthropocentrism that reproduce inequality and contribute to a continued environmental degradation, operating as systems of sociohistorical and economic domination (Esnard \& Cobb-Roberts, 2018).

In a deeper approach to the complexity of this concept, Collins (2015) and Collins and Bilge (2016) reflect on how intersectionality has been conceptualized as everything, from a paradigm, concept, framework, heuristic device, and theory; this heterogeneity is seen by Collins (2019) as both an invitation to examine this concept from many different angles, and as a sign of its dynamism (Collins, 2015). Despite this diversity, Collins and Bilge (2016) identify six core ideas that constantly appear and reappear when people use this analytical tool, providing guideposts for intersectional thinking: social inequality, relationality, power relations, social context, complexity, and social justice. According to Collins (2019), these core constructs (mainly relationality and social justice) uncritically circulate 
within intersectionality, and therefore, she warns us how these ideas must necessarily be analyzed or critically evaluated in any research that takes intersectionality as an analytical strategy.

Taken as a broad-based knowledge project, Collins (2015) has analyzed intersectionality from three focal points: (i) as a field of study that refers to the conceptualization of its history, themes, boundaries, debates, and directions; (ii) as an analytical strategy, i.e., as a tool that provides new angles from which to produce knowledge (Cho et al., 2013), to study inequalities in social institutions, practices, problems, and other social phenomena, and to solve problems that people face (Collins \& Bilge, 2016); and (iii) as a critical praxis, examining the ways in which people produce and use it in their daily lives, and for doing social justice projects by different actors. This multidimensionality of intersectionality has also been expressed as a synergy and creative tension between a critical inquiry and a critical practice, mutually informing each other (Collins \& Bilge, 2016). Similarly to Collins' efforts, intersectionality has been characterized as a method, as a theoretical framework, and as a form of praxis (Cho et al., 2013; Esnard \& Cobb-Roberts, 2018): (i) as a method, intersectionality offers a systematic way of recognizing structural overlaps in the social interaction and the multiple forms and axes of oppression that could be adopted, adapted, and developed within different disciplines; (ii) as a theoretical framework, this notion is an approach that uses multiple axes to examine the social and permits to engage with a wide range of issues (identities, power, discrimination, activism, among others); and (iii) as a form or praxis, it seeks to formulate the basis of social change, from the point of view of the experiences of injustice that confront marginalized groups (Cho et al., 2013; Esnard \& Cobb-Roberts, 2018).

Intersectionality - a term that emerged from feminism and was coined in 1989 by K. Crenshaw ${ }^{1}$ - as Viveros (2016) points out, avoids the risk of repeating mantras in a depoliticized way, such as the multiculturalist one, so common in education (Collins $\&$ Bilge, 2016), because it draws attention to the impossibility of separating different forms of oppression. Intersectionality allows to account for power as a multidimensional phenomenon and for the intersected and interwoven perceptions of these power relations in oppression matrices, which are at the same time racial, sexual, or class based.

\footnotetext{
1 A better understanding of intersectionality requires, from the point of view Collins and Bilge (2016), a careful review of the genealogy of the concept in order to avoid suppressing part of its history by erasing the activism to which it was linked from its origins outside of academia (a history that is frequently omitted), and that rooted the foundational knowledges of women of color who contributed to this concept, and that Harris and Patton (2019, p. 363) have named the "herstory" of this concept.

While it is assumed in academia that the term "intersectionality" was coined and introduced by Crenshaw in 1989 to demonstrate how US social structures frame identities as isolated and mutually exclusive, resulting in the erasure of black women who hold multiple minoritized identities (Harris and Patton, 2019), Collins and Bilge (2016) have specified that the origins of intersectionality date back much further, in the 1960-1970 social movements of women of racially minoritized groups.

Recalling this genealogy makes it easier to understand the link that intersectionality has with the development of a radical and transformative social and educational agenda, because it reveals that at the center of intersectionality, and beyond the intellectual interests, lies the praxis and the theme of social justice (Collins and Bilge, 2016). In this sense, Tefera et al. (2018) and Rice et al. (2019) warn us how intersectionality could be narrowly focused on issues of identity, forgetting that it is mainly a framework to examine and question the power and oppression, and that the intersectional analysis must be committed to social justice: “...intersectionality is not just a set of ideas. Instead, because they inform social action, intersectionality's ideas have consequences in the social world..." (Collins, 2019, p. 2).
} 
From the intersectional perspective, it is assumed that more than one category of oppression is involved in all complex political problems and processes. In addition to being intersected, oppressions are also consubstantial and co-extensive, because each one of them leaves its mark on the others and is constructed in a reciprocal manner, and they all are the result of micro- and macro-sociological articulations (Viveros, 2016). Thus, for example:

...Sometimes gender creates class, as when gender differences produce social stratifications in the workplace. In others, gender relations are used to reinforce social relations of race, such as when indigenous men are feminized or black men are hypermasculinized... (Viveros, 2016, p. 8).

According to Santos (2009), the greatest contribution of scientific literacy in VisionIII would be to prepare citizens for freedom and to build a model of technological development that, instead of sustaining and reproducing oppression, contributes to improving the quality of life of the oppressed people, thus reducing iniquity. Nevertheless, the route delineated by this author concentrates on an image of oppression determined by social class, suppressing the infinite intersections and possible complexities of the structures of injustice and inequality. This deletion also constitutes one of the main criticisms made to Freire's texts when he speaks of oppression (Walsh, 2019).

In the case of Vision-III, Santos (2009) focuses his criticism only on the capitalist structure that sustains current scientific and technological developments, regardless of the oppression matrixes that result when the axis of social class intersects with cultural (racism) or gender (sexism) oppression axes. It makes invisible the fact that opportunities to participate and engage in and with science and transform society are not the same for everyone beyond the social class.

Intersectionality reveals that oppression cannot be reduced to one fundamental type, and given oppressions work together in producing injustice (Collins, 2000), a couple of categories are crucial within an intersectional perspective: matrix of domination and domains of power. The way intersecting oppressions are organized Collins calls (2000 p. 18) "matrix of domination"; the way power works by producing particular patterns of domination Collins names (2000 p. 203) "domains of power," which constitute specific sites where oppressions of race, class, gender, sexuality, and nation mutually construct one another. Formally, Collins (2000 p. 299) defines matrix of domination as:

...the overall organization of hierarchical power relations for any society. Any specific matrix of domination has (1) a particular arrangement of intersecting systems of oppression, e.g., race, social class, gender, sexuality, citizenship status, ethnicity and age; and (2) a particular organization of its domains of power, e.g., structural, disciplinary, hegemonic, and interpersonal...

Collins and Bilge (2016) offer a distinction among the four interconnected domains of power: (i) interpersonal, as discriminatory practices of everyday lived experience of people relating to one another; (ii) disciplinary, as people encountering different treatment regarding different institutional norms and codes; (iii) cultural, the set of ideas and ideologies that provide explanations for social inequality; and (iv) structural, how intersecting power relations of class, gender, race, and nation shape the social. Any particular matrix of domination is organized via these four interrelated domains of power, so each matrix of domination is a historically specific organization of power, within which intersecting oppressions originate, develop, and inhabit; therefore, the domains of power reappear across quite different forms of oppression and diverse local realities (Collins, 2000). 
Consequently, all forms of oppression are interconnected, mutually reinforced, and they perpetuate unequal distributions of resources, power, and privilege among social groups. Given that diverse individuals and groups are situated at particular intersections of oppression, they will have different perceptions, experiences, and configurations of social phenomena (Collins, 2015), including of course, science.

This occurs with science participation, the most characteristic feature of Vision-III. A more in-depth analysis of this idea from the intersectionality perspective provided by sociology shows the need both to broaden this concept, so that all social groups have a place in it, and to specify it in such a way as to facilitate the design and implementation of concrete scientific literacy actions that truly respond to its programmatic content.

Martínez-Palacios and Nicolas-Bach (2016) argue that-behind the studies of social participation-although there is a shared interest in claiming equal access of all social groups to the decision-making processes, it is common to wield a false universality of the notion of participation that prevents the effective development of democratic deepening and, in the case of scientific literacy, the achievement of social equity and educational justice.

This false universality ignores the fact that participatory processes also function according to the logic of the fields of power and that participation, under the intersectional point of view, is crossed by different axes of domination (gender, race, social class, age, among others) (Martínez-Palacios \& Nicolas-Bach, 2016):

...participation does care about gender, but also about race, social class, educational level and age, among other social structures [...]; from which it follows that no definition of participation is culturally neutral and universal; even if we use the same concept we do not employ the same notion... (Martínez-Palacios, 2018, p.

There is a diversity of meanings of what it is to participate, and these depend, among other elements, on the theoretical positioning in the academic field of the agent who enunciates them, and on his or her social position.

According to Martínez-Palacios (2018), there is inertia in the classic and critical theories of democracy, which do not include a reflection on oppression and do employ a restrictive notion of participation as synonymous with political participation, so participation is reduced to the act of voting for the election of political leaders. When this universalized and reduced idea of what it is to participate and deliberate is imposed, an act of power and exclusion of those social groups who do not have the capacity to signify occurs.

Thus, for example, we recognize how different global statistics support that girls continue to be underrepresented in STEM subjects, and women continue to be underrepresented in the STEM workforce (Hammond et al., 2020); however, these gender gaps, which disproportionally affect the most marginalized girls, have been perpetuated in science education probably because we do not have adequate frames that become visible and that make it possible to imagine, register, and document the different and alternative forms women do in fact have and would have to participate in science, showing their talent and potential. Many female scientists are challenging gender stereotypes in science, resisting sexist practices and discrimination, but their ability to resist and rewrite the popular image of science is often minimized, and when an alternative form of agency is not identified, nor registered or named, simply does not exist, the participation of women is consequently diminished or non-existent in many global reports.

In order to make visible the invisible and informal modes of participation, and thus expand the scope of the concept of participation, Martínez-Palacios (2018) identifies three 
images of participation that map its conceptual diversity and reveal its theoretical and practical implications on the educational field. These images are not static and configure a dynamic continuum of mixing and transit among them: (1) a broad conception of participation; (2) a mixed conception; and (3) a restrictive conception of participation (MartínezPalacios, 2018).

In the broad conception of participation, any transformative act is identified as a participatory act, and this includes those that traditionally have had a residual treatment: "...every social act that is projected to build society is participation..." (Martínez-Palacios, 2018, p. 382). The mixed conception of participation assumes that the hegemonic definition of this concept is socially constructed and organizes and divides participation between that which is visible, routine, technified, public, and that which is invisible. The mixed conception recognizes these two forms of participation but gives greater importance to the former.

Martínez-Palacios (2018) recovers the classification of Cunill (1991), who distinguishes among (a) citizen participation (experiences of intervention by individuals in public activities to assert their social interests); (b) political participation (intervention in the structures available to political systems); (c) social participation (which arises from the grouping of individuals in society to defend their interests); and (d) community participation (oriented towards sustaining the community). In this categorization, a distinction is made between the participation to which everybody should aspire, which is considered formal, visible, and with a universal vocation (political and citizen), and informal and invisible participation (community and social), which paradoxically supports the former, but frequently occupies a residual and unrecognized place despite being essential to social life, since it is through it—as Martínez-Palacios (2018) points out—that oppressed groups have been able to learn and demonstrate skills to improve the life conditions of the family, the neighborhood, the town, or the community.

The restrictive conception of participation draws a clear frontier between what is and what is not participation and becomes it a synonym of political participation, excluding and underestimating any intervention or informal activity linked or destined to the care of the community. This conception condenses "...the illusion of the existence of a culturally neutral and universal participation whose technical aspects are underlined, detached from an interpretation or theory about power...”. (Martínez-Palacios, 2018, p. 381).

What does it mean to participate in science within Vision-III? No definition of scientific literacy makes a deep reflection about this conceptual component. By not including a qualification of how science participation is understood within Vision-III, and by not adjectivizing it, it is highly likely that the only concept being considered as participation is the too narrow notion that Martínez-Palacios (2018) characterizes as a supposedly universal notion of participation, “...often used as a synonym for political participation, which would make invisible other forms of participation linked to community or social solidarity, traditionally carried out by women..." (p. 371).

In contrast with the higher education field, where intersectionality has made an increasing contribution (Esnard \& Cobb-Roberts, 2018; Harris \& Patton, 2019; Nichols and Stahl, 2019; Haynes et al., 2020), in the science education field, intersectionality has just been examined, among others, in its relationship with political science faculties (Cabrera, 2014), medical education (Muntinga et al., 2016), mathematical education (Bullock, 2018), geoscience education research (Matheis et al. 2019; Núñez et al., 2020), science identity (Avraamidou, 2020; Castro \& Collins, 2021), and in environmental and sustainability education (Maina-Okori et al., 2018). According to Metcalf et al. (2018, p. 583) “...one reason, apart from the lack of awareness, researchers have not yet adopted intersectionality frameworks for studying STEM participation is that it poses methodological challenges...". 
In geosciences education research, perhaps the field with a relevant progress in intersectionality and science education, Matheis et al. (2019) examined the literature 2008-2018 around intersectionality and inclusivity, with particular interest in the underrepresentation of white women and people of color of all genders in the geosciences. They identified three primary themes that can be synthetized as (a) increased challenges to science as neutral, (b) continued assumptions of meritocracy in higher education, and (c) assimilation as representation. This last theme is relevant for understanding science participation as part of the central argument of this paper, because Matheis et al. (2019) observed that there have been many efforts to increase the representation of women and minoritized racial and ethnic groups in the geosciences, but these efforts attempt to change individuals in order to assimilate them to the school norms; that is to say, these studies have been focused on developing individual skills and capacities to increase success within existing structures, without changing the norms and expectations of the science culture, and without challenging the common culture that structures science itself in educational institutions.

In a similar line of thought, Collins and Bilge (2016) discussed how intersectionality as an analytical framework shed light on the underrepresentation within STEM fields of girls/women and African Americans/Latinos. In their analysis, they propose that intersectionality would increase attention not only on structural barriers to science that these groups face, but also on how the same barriers are experienced differently; intersectional analysis would change the understanding or the underrepresentation in science fields, suggesting that it is more the organization of formal science education itself and its different domains of power (cultural, interpersonal, structural, and disciplinary), and not individual attributes (i.e., cultural capital) that predispose individuals from these groups to higher science achievement.

Other contributions on the issue of the underrepresentation of certain groups in science fields are Sparks (2017), Ireland et al. (2018), Metcalf et al. (2018), and Núñez et al. (2020) who have noticed how social factors, like gender, race, and ethnicity, have been heavily studied, but largely in isolation from one another, while others, like sexuality and disability, have remained mostly absent from the research, policy, and practice. To broaden science participation, they examine the underrepresentation in STEM fields of historically marginalized groups, such as women of color, and apply the intersectionality lens to issue recommendations and expand equity in scientific fields as geosciences. These studies show an increasing need to take advantage of intersectionality as a framework to register not only the barriers that hinder science participation of disadvantaged groups, but also the diverse forms to participate in science that could change the popular images of science and the traditional notion of science participation that could be present in Vision-III of scientific literacy.

Introducing an intersectional perspective to Vision-III allows us to identify new ways of exploring, understanding, and facing the problems of science education and also allows us to make visible the fact that certain activities associated with science and are actually carried out by historically excluded groups, are usually invisible or qualified as non-participation in science, and this is sociologically significant because a different form of participation is not the same as disaffection with science or as a lesser engagement. Intersectionality problematizes, on the one hand, the importance of reviewing what is being registered as an authentic science participation, and that could be omitting and excluding the different subaltern forms of participation that different cultural communities could develop, or, in fact, are already developing in science education. Introducing the intersectional perspective also allows us to create and propose strategies to reduce exclusion in science education, and transform current literacy practices towards more just and accessible to all, with which, depending on the interests and the rational of each culture, it would be possible to 
take advantage of the virtues of science as a social practice of common benefit for a diverse society in which many injustices overlap.

Additionally, in multicultural contexts where science is not a hegemonic activity, I consider that introducing the intersectional perspective into the conceptual analysis of scientific literacy allows us to argue that participation in science should not be discussed under the binomial of participate or not-participate; instead, it is necessary to have a broad concept of participation that, taking into consideration the concrete analysis of social structures and historical and cultural dynamics of different groups, could include the multiple ways in which different social and cultural communities, especially those structurally excluded from science, could participate in science, improving their personal and collective lives, even when these forms of participation do not correspond to the hegemonic ones (civic and political participation). To begin naming and recognizing this diversity in which participation in science is expressed would facilitate the possibility of creating a new narrative for science education, and would foster the design of innovative and more flexible educational environments and science school experiences that also are more sensitive to social and cultural diversities and more inclusive and motivating, so that the populations of students whose lives are spent in environments much more distant from those sets of social codes and norms in which many of the scientific practices take place could become more involved and engaged in science.

Intersectionality, in the same way as critical education and particularly Vision-III revisited here, considers social justice as central to its mission; however, as Collins (2019, p. 2) points out, it has not yet realized its potential as a critical social theory, nor has it adequately democratized its own processes for producing knowledge. Using it as an analytic tool might provide science education research with ".... a more expansive lens for addressing the complexities of educational equity..." (Collins \& Bilge, 2016, p. 188). Its core ideas, such as power and its domains, enable this analytical tool with a huge potential to refocus attention within Vision-III, on the structural organization of science schooling, showing how intersecting power relations, in a contextualized and historicized way, shape "...identities, social practices, institutional arrangements, and cultural representations and ideologies..." (Collins \& Bilge, 2016, p. 202).

In sum, the analytical tasks that intersectionality enable and strengthen for science literacy research are (Dill and Zambrana 2009, cited on Núñez, 2014) (a) to situate as a starting point for educational research the lived experiences of marginalized groups and the often masked pedagogical biases; (b) to explore the social and cultural complexities of individual and collective identities, recognizing those groups that are often ignored and essentialized; (c) to unveil the ways in which domains of power interconnect with each other, organize, and structure inequality and oppression in science education fields; and (c) to promote social and educational justice by linking critical inquiry and practice towards the eradication of oppressions and the advancement of a transformative agenda for the change of social and educational institutions.

\subsection{Emancipation: a Philosophical and Pedagogical Analysis}

Emancipation is one of the other key components of the transformative vision of scientific literacy, and to avoid conceptual ambiguities and mainly to be able to design successful pedagogical actions, it is also necessary to add some conceptual accuracy for a better understanding of the multiple senses of this term. 
The idea of emancipation is nodal in educational theories and practices, even more so in those which considered themselves critical pedagogies (Biesta, 2010, 2017). Emancipation is an ideal historically pursued, which has been transformed over time, to constitute the utopia of transformative education in our days (Romo, 2016).

In emancipation, educators elevate the desire for students to become independent and autonomous, to be able to think for themselves, to make their own judgments and conclusions; this notion embodies the possibilities of changing the oppressive structures in which students are inserted (Biesta, 2010).

Biesta $(2010,2017)$ reviews the historical changes to this notion and finds that emancipation literally means to give away ownership (ex: away; mancipum: ownership). In Roman law, it referred to the freeing of a son or wife from the legal authority of the father-pater familias (Gross, 2010) — an imprint that marks its bond with education, in the sense that emancipation defines the moment when a child (dependent) becomes an adult (independent). In more general terms, it refers to the freeing of someone from the authority or control of another, which implies that the object of emancipation (person to be emancipated) is released and becomes independent as a result of the act of emancipation (Biesta, 2010).

According to the Real Academia Española (Romo, 2016), emancipation is freeing from any kind of subordination or dependence. From being used in relation to religion (seventeenth century), emancipation shifted its focus to slaves (eighteenth century), and to women and workers (nineteenth century). During the enlightenment, in the eighteenth century and as a key concept present in Kant's texts, emancipation became linked to the idea of man's release from his self-incurred tutelage, that is, from his immaturity or "....inability to make use of his understanding without the direction of another..." (Biesta, 2010, p. 42). Becoming enlightened implied becoming independent or autonomous, and for Kant, this autonomy was the ultimate goal for a human being, that is, the use of one's reason, a capacity that could only be possible through education. Following Biesta (2010), Kant differentiated between immaturity and maturity and this distinction maps onto the difference between childhood and adulthood; only through education can one move from one to the other.

After World War II, it was assumed that there would be no individual emancipation without a broader transformation of society, and this was central to the historical evolution of critical traditions of education during the 1960s (Gross, 2010). By occupying a key position as a hinge between old and new generations, education became strategic to critical theories, interested in analyzing the structures and practices of oppression, to argue that emancipation would only take place by unveiling (or demystifying) the power relations in which individuals are embedded (Biesta, 2010).

Biesta $(2010,2017)$ strongly criticizes the traditional notion of emancipation which, contradicting its origin, ends up reproducing the power and hierarchical relations between the agents who participate in a pedagogical relationship; instead, Biesta takes up and reconstructs contributions such as those of Rancière $(2003,2009)$ to delineate a different and alternative approach to emancipation.

According to Biesta (2010, 2017), there is an argumentative strand within the critical tradition in which it is argued that emancipation can only be brought about "from the outside," that is, from a position uncontaminated by the workings of power; from this point of view, emancipation functions as a process of demystification and liberation from dogmatism. This line of thought goes back to Marxist notions of ideology and false consciousness, in which to free ourselves from the oppressive functioning of power we need to expose our consciousness to how power operates, but in addition, we need someone else, whose consciousness is not subjected to the workings of power, to provide us with 
an explanation of our objective condition. That is, the truth of our objective condition can only be generated by someone who is "outside" the influence of ideology (and, of course, this "someone" could be science itself). Following Biesta (2010), the task of critical educators is to make visible what is hidden to those who are the object of their emancipatory efforts; in the same way, the task of critical social science is to make visible what is hidden from the everyday view.

Following this logic, Biesta (2010) highlights some philosophical features of emancipation that condition it and determine it to a certain pedagogical logic: (1) that emancipation requires an intervention from the outside by someone not subjected to the power to be defeated; (2) that emancipation is based on an inequality and asymmetry present between emancipator and emancipated; (3) that equality is the-future and expected-result of emancipation, but not its starting point.

Biesta (2010) systematizes the contradictions of this emancipatory logic: (1) although emancipation is oriented towards equality, independence, and freedom, it instills a dependence on the emancipatory act; without intervention, there is no emancipation, and whoever is emancipated depends on the intervention of the emancipator, who possesses knowledge inaccessible to the former; (2) emancipation is based on a fundamental inequality between the emancipator and the emancipated; the former occupies a superior position, since he is the one who knows best and who can best perform the act of demystification required to reveal the functioning of power; (3) emancipation is based on the distrust and suspicion of the emancipator about the limitations of his own experiences, and this makes it necessary for an emancipator to tell the emancipated the truth about what he is really experiencing, about his situation and his real problems.

As an alternative to resolve these tensions, Biesta (2010) reminds us that the relationship of dependence that is established with this idea of emancipation, and that is constitutive of Western philosophy and social theory, has been questioned by Rancière (2003, 2009), who shows that thinking of the emancipatory process in this way involves a logic of dependence in which he who is emancipated remains dependent on the truth or knowledge about their conditions of oppression that will be revealed by the emancipator.

For Rancière, emancipation is escaping from a minority. With this alternative definition, he places, on the one hand, the act of emancipation in the emancipated because "... nobody escapes from the social minority save by their own efforts..." (Biesta, 2010, p. 46), and, on the other hand, he links this act to a process of subjectification, which causes a rupture with the established order. The emergence of a subjectivity through education produces a declassification or desidentification, to the extent that the emerging (emancipated) subject is declassified with respect to the social order through the exercise of his or her rational capacity (Madrid 2012). Likewise, Rancière assumes that equality is not a goal to be reached with emancipation, but that emancipation acts on the basis of presupposing equality (of intelligence of all human beings), in order to maximize it: “...central to emancipation, therefore, is the awareness of what an intelligence can do when it considers itself equal to any other and considers any other equal to itself..." (Biesta, 2010, p. 55). His proposal of the "ignorant schoolmaster" constitutes this instance of emancipation (Madrid 2012).

Besides the analysis made by Biesta (2010) about Rancière's work, we could add the comparative studies between Freire and Rancière (Biesta, 2017; Galloway, 2012) which emphasize the importance of having to always specify how emancipation is conceived when talking about it in education. Freire and Rancière coincide in criticizing 
the modern logic of emancipation, but it should be noted that they came to similar assumptions through different paths, and with different results. Galloway and Biesta show that, depending on how oppression and emancipation are understood, these logics will have different pedagogical implications on the character of the relationship that will be established between teachers and students, and on the teachers' role in the emancipatory process.

Such implications are not explicit in the definition of scientific literacy proposed in Vision-III, since there is not a precise description of the kind of emancipation that is necessary to transform society based on students' science participation.

Santos (2009) emphasizes that scientific literacy should include discussions about the conditions of oppression present in the society where science is developed, since that is the context where its humanistic character lies. Adopting the Freirean formula of reading the world and sharing it with others in order to build and rebuild it, Santos proposes that scientific literacy should consist of identifying the socially relevant issues to be discussed; discussing them through dialogue, highlighting the contradictions that science has in society, and debating the actions required for its transformation, committing students to these socio-political actions- that is, to a political agenda. This logic, in which the student realizes "the objective facts" such as, for example, that few enjoy the benefits of technologies, while two-thirds of the world's population cannot access them, or do not even have the most basic conditions for a dignified life (Santos, 2009), seems to carry with it a limited emancipatory logic based on the dependence of superior knowledge possessed by the emancipator, silencing the cultural difference in which science takes place. If this idea of emancipation stays at the basis of Vision-III, it would be more difficult to achieve the transformative aims that scientific literacy sets out to attain.

It is mostly in multicultural contexts that an expanded concept of emancipation is of particular relevance for science teaching, because it has played a prominent role in the colonial process (Burke \& Wallace, 2020); it is common in these contexts for science to present itself as the only legitimate and emancipatory knowledge, competing and erasing the various alternative forms of knowledge that have been generated outside the European scientific matrix (Zidny et al., 2020) and excluding cultural diversity in the science classroom. Approaching science as a liberating and emancipating force that frees humans from local beliefs, myths, and ideologies in contexts where different forms of knowledge coexist (personal, popular, indigenous, traditional, rural, and mainstream academic knowledge) carries the risk of reinforcing a scientism and a neocolonialism that are commonly expressed as the educational effort of displacement, eradication, or substitution of alternative forms of knowledge for scientific knowledge, regardless of the potential value that these alternative forms of knowledge might have in the VUCA world to cope with the environmental, social, and economic challenges that we currently face.

In order to achieve a transformative education that facilitates a sustainable future and more just, equitable, and plural societies, I sustain that it is necessary to design scientific literacy experiences that allow students to understand, value, and relate to the world differently in their everyday lives, not only through canonic scientific ideas, but (a) fostering the dialogical and respectful exchange of diverse perspectives on the social and natural world; (b) taking advantage of the best of the different alternative forms of knowledge; and (c) cultivating their engagement, both with science and with their communities and cultures of origin. As students are educated for emancipation, as Feyerabend said, “... they will become scientists without having been taken in by the ideology of science, they will be 
scientists because they have made a free choice..." (Feyerabend, 1975: 310). In this sense, scientific literacy for emancipation implies learning not only to read and write scientific texts, but also the appropriation of the scientific language to express their own intentions and to become authors and agents that define their own place in the social and natural world; that means, scientific literacy is then a social practice and a tool for the self-construction of one's voice and place in the world (Hernández, 2019).

\section{Conclusions}

In the aftermath of the pandemic, there has been a consensus among different countries that scientific literacy is vital and strategic to meet the global challenges ahead. It is widely accepted that scientific knowledge and scientific thinking are essential to participate in democracy and, in general, to make decisions about global risks. However, the engagement of children and young people with science subjects in school is continuously declining around the world. Research suggests that cultural diversity issues lie behind this permanent crisis in scientific literacy (Mansour \& Wegerif, 2013), not only diversity in gender, social class, and ethnicity, but also the diversity of ways in which new generations establish relations with scientific knowledge, and that go beyond opting to study a scientific career.

The diversity of individual and collective ways of living and relating to science means that the meaning of becoming literate in science has been moving from a transmissive and propaedeutic vision to a transformative vision engaged with socioscientific activism (Bencze, 2017). However, the transformative vision continues to have some difficulties in the way we conceive of it and concretize it into effective educational practice, if we do not consider, from an interdisciplinary point of view, the diversity of meanings that its conceptual components could have, not only according to the contexts and communities in which we live, but also according to the social roles that we choose or are assigned by others (Mansour \& Wegerif, 2013).

Different policy documents from OECD and UNESCO have been stressing the need to prepare students for the VUCA world (Hadar et al., 2020), in which existing institutions and social structures appear to be insufficient to overcome the new situations. The VUCA world demands a science education that is more socially committed to the transformation of social oppression and a science education that broadens the agency capacity of individuals and communities to take advantage of science in the generation of adaptative, resilient, and sustainable responses to unpredictable changes of today. The preparation of autonomous and emancipated individuals committed to participating in science must translate into more opportunities to respond to the VUCA world, as it requires more flexibility, resilience, and sustainability in decision-making and more creative actions that take advantage of multiple ways in which the best of science and cultures could be used to achieve a positive and necessary social change for a society in crisis.

The conceptual analysis presented in this paper intends to show the need to continue rethinking and reconceptualizing scientific literacy in such a way that makes it possible to recover its most fundamental sense but also including its derived sense in an interdisciplinary manner more compatible with the diversity of conflicted, cultural, and social experiences in which students and teachers are inserted and which, from the beginning, make more or less incompatible their lives with the processes of science teaching and learning.

Given that not all the actors who define what scientific literacy is share the same senses, values, and aims of what is socially desirable, the concept of scientific literacy remains 
multivocal and its understanding and evaluation requires a more precise identification about the axiological, sociological, ethical-political, and pedagogical commitments that are behind each conception proposed for this term, insofar as these conceptions express “...programs of action..." (Norris et al., 2014, p. 1319).

Science participation and emancipation are not homogeneous, and students are not an undifferentiated mass of people that exists beyond social divisions of race, gender, age, among others; unmasking positions and power is relevant to broadening the scope and understanding of the components of Vision-III of scientific literacy.

Throughout this text, there has been an argument for the need to recover the fundamental sense of scientific literacy, on the one hand, and on the other, for the need to deepen and strengthen its derived sense, introducing in it an intersectional and emancipatory perspective that by definition is anti-scientificist, antiracist, and anti-neocolonialist. When certain facts of educational reality do not fit into the current conceptual frameworks, it is necessary to rethink these frameworks and propose the incorporation of new ones. Adding extended concepts of participation and emancipation would contribute to make visible and make it possible to recognize the diversity of actors, of emerging practices and activities committed to science, whose agency is not only challenging the hegemonic image and the dominant system of science, but also is rewriting the whole of actions that actually function as producers of innovative and unique solutions to social problems, based on science and at the same time on different forms of knowledge, which together configure new plural and dialogic scientific practices, refreshing science education as a motor for social and community transformations, mainly in structurally vulnerable and unseen contexts, that frequently are excluded from the more traditional views of scientific literacy.

Science is more than the declarative knowledge it generates, and the fundamental sense of literacy reminds us the essential role, now diluted, of scientific texts, and it also allows us to acknowledge the social and epistemic functions of reading and writing science as social, interactive, iterative, regulated, and negotiated practices in which substantive scientific knowledge is constructed. Reading and writing in the scientific disciplines implies teaching and learning strategies for understanding, interpreting, reinterpreting, analyzing, criticizing (Norris \& Phillips, 2003; Norris et al., 2014), and, of course, elaborating scientific texts, and this is what their fundamental sense points out.

Likewise, in its derived sense, scientific literacy is a potential tool for social transformation, and it certainly requires the participation of all citizens and their emancipation. But not of a limited participation narrowly conceived as a synonym of formal, political, and citizen participation, but of a more inclusive participation that makes visible the invisible and informal contributions of diverse social groups that have been historically vulnerable and usually excluded from science and technology. Similarly, to be transformative, scientific literacy requires a commitment to an alternative notion of emancipation that avoids generating dependencies that assign, in a contradictory way, roles of superiority to science teachers and to science itself that are mostly frequent in multicultural contexts.

Funding This research was supported by UNAM-DGAPA-PAPIIT IG400920.

Data Availability Not applicable.

Code Availability Not applicable. 
Declarations

Competing interests The author declares no competing interests.

\section{References}

Aikenhead, G. (2006). Science education for everyday life: evidence-based practice. Teachers College Press.

Avraamidou, L. (2020). Science identity as a landscape of becoming: rethinking recognition and emotions through an intersectionality lens. Cultural Studies of Science Education, 15, 323-345.

Bee, C., \& Kaya, A. (2017). Youth and active citizenship in Turkey: engagement, participation and emancipation. Southeast European and Black Sea Studies, 17(1), 129-143.

Bencze, L. (2017). Science and technology education promoting wellbeing for individuals, societies and environments. Springer.

Bennett, N., \& Lemoine, G. J. (2014). What a difference a word makes: understanding threats to performance in a VUCA world. Business Horizons, 57(3), 311-317.

Biesta, G. (2010). A new logic of emancipation: the methodology of Jacques Rancière. Educational Theory, 60, 39-59.

Biesta, G. (2017). Don't be fooled by ignorant schoolmasters: on the role of the teacher in emancipatory education. Policy Futures in Education, 15(1), 52-73.

Bullock, E. (2018). Intersectional analysis in critical mathematics education research: a response to figure hiding. Review of Research in Education, 42(1), 122-145.

Burke, L. A., \& Wallace, J. (2020). Re-examining postcolonial science education within a power-knowledge framework. Science \& Education, 29, 571-588.

Bybee, R. (2016). Scientific literacy. In R. Gunstone (Ed.), Encyclopedia of science education (pp. $944-$ 946). Springer.

Cabrera, A. (2014). Toward an intersectional political science pedagogy. Journal of Political Science Education, 10(1), 102-116.

Castro, A., \& Collins, C. (2021). Asian American women in STEM in the lab with "White Men Named John." Science Education, 105(1), 33-61.

Chang, M., Singh, K., \& Mo, Y. (2007). Science engagement and science achievement: longitudinal models using NELS data. Educational Research and Evaluation, 13(4), 349-371.

Cho, S., Crenshaw, K., \& McCall, L. (2013). Toward a field of intersectionality studies: theory, applications, and praxis. Signs: Journal of Women in Culture and Society, 38(4), 785-810.

Choi, K., Lee, H., Shin, N., Kim, S., \& Krajcik, J. (2011). Re-conceptualization of scientific literacy in South Korea for the 21st century. Journal of Research in Science Teaching, 48(6), 670-697.

Collins, P. H. (2000). Black feminist thought: knowledge, consciousness, and the politics of empowerment. Routledge.

Collins, P. H. (2015). Intersectionality's definitional dilemmas. Annual Review of Sociology, 41, 1-20.

Collins, P. H. (2019). Intersectionality as critical social theory. Duke University Press.

Collins, P. H., \& Bilge, S. (2016). Intersectionality. Polity Press.

Cunill, N. (1991). Participación ciudadana, dilemas y perspectivas para la democratización de los estados latino americanos. CLAD.

DeBoer, G. E. (2000). Scientific literacy: another look at its historical and contemporary meanings and its relationship to science education reform. Journal of Research in Science Teaching, 37(6), 582-601.

DeWitt, J., \& Archer, L. (2017). Participation in informal science learning experiences: the rich get richer? International Journal of Science Education, Part B, 7(4), 356-437.

Esnard, T., \& Cobb-Roberts, D. (2018). Black women in higher education: toward comparative intersectionality. In T. Esnard \& D. Cobb-Roberts (Eds.), Black women, academe, and the tenure process in the United States and the Caribbean (pp. 99-133). Palgrave.

Feyerabend, P. (1975). Cómo defender a la sociedad contra la ciencia, in I. Hacking (comp.). Revoluciones científicas (pp. 294-314). FCE.

Fredricks, J. A., Blumenfeld, P. C., \& Paris, A. H. (2004). School engagement: potential of the concept, state of the evidence. Review of Educational Research, 74(1), 59-109.

Galloway, S. (2012). Reconsidering emancipatory education: staging a conversation between Paulo Freire and Jacques Rancière. Educational Theory, 62(2), 163-184. 
Gibbons, M., Limoges, C., Nowotny, H., Schwartzman, S., Scott, P., \& Trow, M. (1997). La nueva producción del conocimiento. Ediciones Pomares.

Gottesman, I. (2016). The critical turn in education: from Marxist critique to postestructuralist feminism to critical theories of race. Routledge.

Grabau, L., \& Ma, X. (2017). Science engagement and science achievement in the context of science instruction: a multilevel analysis of U.S. students and schools. International Journal of Science Education, 39(8), 1045-1068.

Gross, S. (2010). Inequality and emancipation: an educational approach. Journal of Education and Research, 2, 9-16.

Hadar, L., Ergas, O., Alpert, B., \& Ariav, T. (2020). Rethinking teacher education in a VUCA world: student teachers' social-emotional competencies during the Covid-19 crisis. European Journal of Teacher Education, 43(4), 573-586.

Hammond, A., Rubiano, E., Beegle, K., \& Kumaraswamy, S. (2020). The equality equation. Advancing the participation of women and girls in STEM. World Bank.

Harris, J., \& Patton, L. (2019). Un/Doing Intersectionality through higher education research. The Journal of Higher Education, 90(3), 347-372.

Haynes, C., Joseph, N., Patton, L., Stewart, S., \& Allen, E. (2020). Toward an understanding of intersectionality methodology: a 30-year literature synthesis of Black women's experiences in higher education. Review of Educational Research, 90(6), 751-787.

Hernández, G. (2019). De los nuevos estudios de literacidad a las perspectivas decolonialesen la investigación sobre literacidad. Íkala Revista de lenguaje y cultura, 24(2), 363-386.

Hodson, D. (2003). Time for action: science education for an alternative future. International Journal of Science Education, 25(6), 645-670.

Hodson, D. (2009). Teaching and learning about science: language, theories, methods, history, traditions and values. Sense.

Hodson, D. (2011). Looking to the future: building a curriculum for social activism. Sense.

Hoffman, D., Perillo, P., Hawthorne, L., Hadfield, J., \& Lee, D. M. (2005). Engagement versus participation: a difference that matters. About Campus, 10(5), 10-17.

Ireland, D., Freeman, K., Winston-Proctor, C., DeLaine, K., McDonald, S., \& Woodson, K. (2018). (Un) Hidden figures: a synthesis of research examining the intersectional experiences of Black women and girls in STEM education. Review of Research in Education, 42(1), 226-254.

Johnston, P., Beaudoin, C., Jones, L., \& Waggett, R. (2015). Student engagement or simply participation: how does a beginning teacher know? Kappa Delta Pi Record, 51(2), 90-92.

Lee, H., Yoo, J., Choi, K., Kim, S., Krajcik, J., Herman, B., \& Zeidler, D. (2013). Socioscientific issues as a vehicle for promoting character and values for global citizens. International Journal of Science Education, 35(12), 2079-2113.

Levinson, R. (2010). Science education and democratic participation: an uneasy congruence? Studies in Science Education, 46(1), 69-119.

Liu, X. (2009). Beyond science literacy: science and the public. International Journal of Environmental \& Science Education, 4(3), 301-311.

Liu, X. (2013). Expanding notions of scientific literacy: a reconceptualization of aims of science education in the knowledge society. In N. Mansour \& R. Wegerif (Eds.), Science education for diversity (pp. 23-39). Springer.

Maina-Okori, N. M., Koushik, J. R., \& Wilson, A. (2018). Reimagining intersectionality in environmental and sustainability education: a critical literature review. The Journal of Environmental Education, 49(4), 286-296.

Mansour, N., \& Wegerif, R. (2013). Why science education for diversity? In N. Mansour \& R. Wegerif (Eds.), Science education for diversity (pp. ix-xx). Springer.

Martínez-Palacios, J. (2018). ¿Qué significa participar? Reflexiones sobre la construcción de las imágenes de la participación. Papers, 103(3), 367-393.

Martínez-Palacios, J., \& Nicolas-Bach, J. (2016). Mujeres y democracia participativa: ¿qué impide los proyectos de participación de las mujeres? Revista Mexicana de Sociología, 78(3), 497-527.

Matheis, A., Murphy, M., \& Marin-Spiotta, E. (2019). Examining intersectionality and inclusivity in geosciences education research: a synthesis of the literature 2008-2018. Journal of Geoscience Education, 67(4), 505-517.

Metcalf, H., Russell, D., \& Hill, C. (2018). Broadening the science of broadening participation in STEM through critical mixed methodologies and intersectionality frameworks. American Behavioral Scientist, 62(5), 580-599.

Montero, M. (2004). Introducción a la psicología comunitaria: desarrollo, conceptos y procesos. Paidós. 
Muntinga, M., Krajenbrink, V., Peerdeman, S., Croiset, G., \& Verdonk, P. (2016). Toward diversityresponsive medical education: taking an intersectionality-based approach to a curriculum evaluation. Advances in Health Sciences Education, 21, 541-559.

Nguyen, A., \& Catalan-Matamoros, D. (2020). Digital mis/disinformation and public engagement with health and science controversies: fresh perspectives from Covid-19. Media and Communication, 8(2), 323-328.

Nichols, S., \& Stahl, G. (2019). Intersectionality in higher education research: a systematic literature review. Higher Education Research \& Development, 38(6), 1255-1268.

Norris, P., Phillips, L., \& Burns, D. (2014). Conceptions of scientific literacy: identifying and evaluating their programmatic elements. In M. Matthews (Ed.), International handbook of research in history (pp. 1317-1344). Springer.

Norris, S., \& Phillips, L. (2003). How scientific literacy in its fundamental sense is central to scientific literacy. Science Education, 87(2), 224-240.

Norris, S. , \& Phillips, L. (2016). Scientific literacy: its relationship to "literacy". Encyclopedia of science education. https://link.springer.com/content/pdf/10.1007\%2F978-94-007-6165-0_179-1.pdf. Accessed 30 July 2020.

Núñez, A. M. (2014). Advancing an intersectionality framework in higher education: power and Latino postsecondary opportunity. In M. Paulsen (Ed.), Higher Education: Handbook of Theory and Research (pp. 33-92). Springer.

Núñez, A. M., Rivera, J., \& Hallmark, T. (2020). Applying an intersectionality lens to expand equity in the geosciences. Journal of Geoscience Education, 68(2), 97-114.

Orozco, B. (2020). Interrogar el sentido del conocimiento escolar ante la pandemia. Perfiles educativos, XLII(170), 63-71.

Pedretti, E., \& Nazir, Y. (2011). Currents in STSE education: mapping a complex field. Science Education, 95(4), 601-626.

Rancière, J. (2003). El maestro ignorante. Cinco lecciones sobre la emancipación intelectual. Laertes.

Rancière, J. (2009). El espectador emancipado. Manantial.

Rice, C., Harrison, E., \& Friedman, M. (2019). Doing justice to intersectionality in research. Cultural Studies $\leftrightarrow$ Critical Methodologies, 19(6), 409-420.

Roberts, D. (2007). Scientific literacy/science literacy. In S. Abell. N. Lederman (Eds.), Handbook of research on science education (pp. 729-780). Lawrence Erlbaum.

Romo, M. (2016). Emancipación. Diccionario Iberoamericano de Filosofía de la Educación. Fondo de Cultura Económica. https://www.fondodeculturaeconomica.com/dife/definicion.aspx?1=E\&id=36. Accessed 30 July 2020.

Sadler, T., \& Dawson, V. (2012). Socio-scientific issues in science education: contexts for the promotion of key learning outcomes. In B. J. Fraser (Ed.), Second International Handbook of Science Education (pp. 799-809). Springer.

Sánchez, H., \& Gil, I. (2015). Análisis interseccional y enfoque intercultural en el estudio de la ciudadanía y la participación. Diálogo Andino, 47, 143-149.

Santos, W. (2009). Scientific literacy: a Freirean perspective as a radical view of humanistic science education. Science Education, 93(2), 361-382.

Sensoy, Ö., \& DiAngelo, R. (2017). Is everyone really equal? An introduction to key concepts in social justice education. Teachers College Press.

Shamos, M. (1995). The myth of scientific literacy. Rutgers University Press.

Shen, B. (1975). Scientific literacy and the public understanding of science. In S. Day (Ed.), Communication of scientific information (pp. 44-52). S. Karger AG.

Sjöström, J., \& Eilks, I. (2018). Reconsidering different visions of scientific literacy and science education based on the concept of Bildung. In Y. Dori (Ed.), Cognition, Metacognition, and Culture in STEM Education (pp. 65-88). Springer.

Sparks, D. (2017). Navigating STEM-worlds applying a lens of intersectionality to the career identity development of underrepresented female students of color. Journal for Multicultural Education, $11(3), 162-175$

Tefera, A., Powers, J., \& Fischman, G. (2018). Intersectionality in education: a conceptual aspiration and research imperative. Review of research in education, 42(1), vii-xvii.

UNESCO (2020). Education in a post-COVID world: nine ideas for public action. https://unesdoc.unesco.org/ark:/48223/pf0000373717/PDF/373717eng.pdf.multi. Accessed 30 July 2020.

Viveros, M. (2016). La interseccionalidad: una aproximación situada a la dominación. Debate Feminista, $52,1-17$.

Walsh, C. (2019). (Decolonial) Notes to Paulo Freire: walking and asking. In R. Aman \& T. Ireland (Eds.), Educational alternatives in Latin America (pp. 207-230). Palgrave. 
Wong, B. (2016). Minority ethnic students and science participation: a qualitative mapping of achievement, aspiration, interest and capital. Research in Science Education, 46, 113-127.

Woods-McConney, A., Oliver, M. C., McConney, A., Schibeci, R., \& Maor, D. (2014). Science engagement and literacy: a retrospective analysis for students in Canada and Australia. International Journal of Science Education, 36(10), 1588-1608.

Yore, L. (2012). Science literacy for all: more than a slogan, logo, or rally flag! In K. Tan \& M. Kim (Eds.), Issues and challenges in science education research (pp. 5-23). Springer.

Zeidler, D., Herman, B., \& Sadler, T. (2019). New directions in socioscientific issues research. Disciplinary and Interdisciplinary Science Education Research, 1, 1-11.

Zeidler, D., \& Nichols, B. (2009). Socioscientific issues: theory and practice. Journal of Elementary Science Education, 21(2), 49-58.

Zidny, R. J., Sjöström, J., \& Eilks, I. (2020). A multi-perspective reflection on how indigenous knowledge and related ideas can improve science education for sustainability. Science \& Education, 29, 145-185.

Publisher's Note Springer Nature remains neutral with regard to jurisdictional claims in published maps and institutional affiliations. 